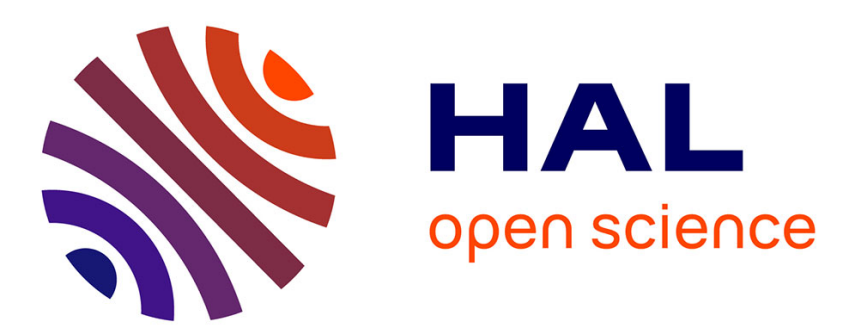

\title{
On the Robust Control of DC-DC Converters: Application to a Hybrid Power Generation System
}

David Hernández-Torres, Olivier Sename, Delphine Riu, Florence Druart

\section{To cite this version:}

David Hernández-Torres, Olivier Sename, Delphine Riu, Florence Druart. On the Robust Control of DC-DC Converters: Application to a Hybrid Power Generation System. SSSC 2010 - 4th IFAC Symposium on System, Structure and Control, Sep 2010, Ancona, Italy. pp.WeCT1.1, 10.3182/201009153-IT-2017.00010 . hal-00504592

\section{HAL Id: hal-00504592 \\ https://hal.science/hal-00504592}

Submitted on $20 \mathrm{Jul} 2010$

HAL is a multi-disciplinary open access archive for the deposit and dissemination of scientific research documents, whether they are published or not. The documents may come from teaching and research institutions in France or abroad, or from public or private research centers.
L'archive ouverte pluridisciplinaire HAL, est destinée au dépôt et à la diffusion de documents scientifiques de niveau recherche, publiés ou non, émanant des établissements d'enseignement et de recherche français ou étrangers, des laboratoires publics ou privés. 


\title{
On the Robust Control of DC-DC Converters: Application to a Hybrid Power Generation System
}

\author{
David Hernández-Torres ${ }^{* * *}$ Olivier Sename ${ }^{* *}$ Delphine Riu* \\ Florence Druart ${ }^{* * *}$ \\ * G2Elab, Grenoble Electrical Engineering Laboratory \\ CNRS - UMR 5269, 38402 St-Martin-d'Hères Cedex France \\ (e-mail: david.hernandez,delphine.riu@g2elab.grenoble-inp.fr) \\ ** GIPSA-Lab, Grenoble Department of Control Systems \\ CNRS - UMR 5216, 38402 St-Martin-d'Hères Cedex France \\ (e-mail: olivier.sename@gipsa-lab.grenoble-inp.fr) \\ *** LEPMI, Grenoble Laboratory of Electrochemistry and \\ Physical Chemistry of Materials and Interfaces \\ CNRS - UMR 5631, 38402 St-Martin-d'Hères Cedex France \\ (e-mail: florence.druart@lepmi.grenoble-inp.fr)
}

\begin{abstract}
In this paper a complete robust control synthesis is performed for a hybrid power generation structure composed by a Fuel Cell and a Supercapacitor. The control strategies are applied to the DC-DC boost power converters associated to each power source. Multivariable PI control with $\mathcal{H}_{\infty}$ performance, $\mathcal{H}_{\infty}$ full and reduced order controllers are designed and compared. The multivariable PI controller is designed through an optimization procedure based on solving some Linear Matrix Inequalities. A $\mu$-analysis and frequency/time response performances results shows the advantages of the different proposed control strategies.
\end{abstract}

Keywords: Robust Control, Multivariable Control, Linear Matrix Inequalities, Fuel Cells, Supercapacitors, Hybrid Power Generation.

\section{INTRODUCTION}

It is believed that there will be a time in the future when global energy demands will be met by some sources of energy other than fossil fuels. Thus, Fuel Cells (FC), in particular Proton Exchange Membrane Fuel Cells (PEMFC), are expected to play a major role in the future energy sector. PEMFC are particularly attractive for use in vehicles as a replacement to the internal combustion engines. They also seem to be a promising source to be used in residences, industries and small- and large-scale distributed generation systems. The low operating temperature of a PEMFC (typically $<90^{\circ} \mathrm{C}$ ) allows easy start-up and fast response to load variations and operating conditions. Nevertheless, several issues need to be resolved before FC can be commercially viable. Indeed, the need of precise water management, the dehydration of membrane, the complex electrode kinetics, the mass transport and the slow rate of oxygen reduction are the most significant limiting factors on the FC performances. Beyond the understanding of physical phenomena in the $\mathrm{FC}$ and the description of their steady state and dynamic behaviours, the control of FC systems has become more and more important over the years in order to improve performance and efficiency of the FC integrated in a power system.

The control strategies proposed in this paper are applied to the power converters of a hybrid power generation system composed by a FC and a Supercapacitor (SC).
A complete review of FC models proposed in literature, is presented in Hissel et al. (2008). The coordination of several power converter control configurations and FC system considerations are presented in Pera et al. (2007) and Suh and Stefanopoulou (2005). Control strategies often include FC energy efficiency management, see Song et al. (2007) for an example. Classically, each component of the FC system is controlled independently of other components. This approach allows simplifying the control strategy, but is not sufficient to take into account the various dynamics of the system and the coupling between thermodynamics (gas pressure) and electric (DC current or voltage) variables. Moreover, time spent for the design of the system can become critical since it is often necessary to come back over the calculation of controller parameters. This is why multivariable robust control is proposed.

Multivariable Multiple Input-Multiple Output (MIMO) robust control in these type of system has already been studied in literature, as in Gadoura et al. (2002) and Rafiei et al. (2003), where robust $\mathcal{H}_{\infty}$ is proposed. However, application to the real model and order reduction is not addressed. High order controllers are also computed using state feedback, as in Takegami et al. (2004). In Petrovic and Rakic (2005), or even Alvarez-Ramirez et al. (2001), in addition to full order $\mathcal{H}_{\infty}$ control, simple ProportionalIntegral (PI) control is proposed, however robust performance criteria in the PI control synthesis and the MIMO case are not considered. Robust control is interesting given 
some special characteristics of power converters, such as high non-linearities (discontinuities) or highly variable parameters (system load). Besides this, components suppliers and manufacturers should be able to design their equipment while knowing precisely the parameters of the whole system. But, FC performances are closely linked with temperature and membrane humidification. For that purpose, robustness methods seem to be particularly adapted since they are able to deal with control issues for uncertain systems.

A high number of power converter control designs are based on Pulse-width-modulation (PWM) control. PWM of DC-DC boost converters is generally divided in two approaches: voltage-mode and current-mode control. Boost power converters dynamics includes right-hand-side (RHS) zero. To provide more damping to the system, in the current-mode control an additional stabilizing current loop is used. The control then becomes a multi-loop feedback problem, see Middlebrook (1987) and Alvarez-Ramirez et al. (2001). The problem becomes more complex when multivariable control is needed for several parallel connected converters, as is the case of hybrid power generation systems. Within this context, several linear robust control techniques are designed and compared in this paper, but more importance is given to small order controllers (PI and Reduced order $\mathcal{H}_{\infty}$ control) due to their simplicity in practical industrial application. Reduced order $\mathcal{H}_{\infty}$ controllers are proposed following Gumussoy et al. (2009). To include robust performance specifications in the PI control synthesis proposed in this paper, the control problem is written as a Linear Matrix Inequalities (LMI) convex optimization problem. The iterative LMI (iLMI) method proposed in $\mathrm{He}$ and Wang (2006) is used to solve the MIMO PI control problem for given desired $\mathcal{H}_{\infty}$ performance. The proposed controllers are simulated and validated using both, the non-linear average model and the topological model of the power converters.

The paper is divided in five sections. In the first section a theory review of the proposed control strategies is presented. Then, in the second section, the hybrid power generation system is presented. And finally, in the last three sections, proposed control synthesis, results and robustness analysis are shown.

\section{CONTROL STRATEGIES}

In this section the different control strategies proposed in this paper are reviewed. These control techniques are applied to a state-space system arranged in the general control configuration (shown in Fig. 1) and described by the following set of equations:

$$
\begin{gathered}
\dot{x}=A x(t)+B_{1} \omega(t)+B_{2} u(t) \\
z(t)=C_{1} x(t)+D_{11} \omega(t)+D_{12} u(t) \\
y(t)=C_{2} x(t)+D_{21} \omega(t)
\end{gathered}
$$

with $x(t) \in \mathbb{R}^{n}$ the state variables, $\omega(t) \in \mathbb{R}^{r}$ the external input, $u(t) \in \mathbb{R}^{m}$ the control input, $z(t) \in \mathbb{R}^{q}$ is the controlled output and $y(t) \in \mathbb{R}^{p}$ the measured output.

This linear model (1) can be extended to include the performance and robustness specifications, as done in the $\mathcal{H}_{\infty}$ approach. Particularly, some weighting functions can be included in the control design model in order to represent some templates on the sensitivity functions or to model the system uncertainties, as illustrated in Skogestad and Postlethwaite (1996).

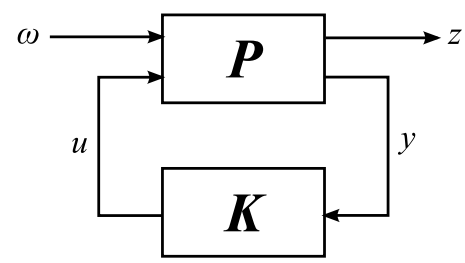

Fig. 1. General Control Configuration.

\subsection{Multivariable PI Control with $\mathcal{H}_{\infty}$ Performance}

The proposed control strategy to design a multivariable PI controller, is based on solving some imposed LMI's constraints to the system (1) using the iterative algorithm proposed in He and Wang (2006). In terms of simplicity and performance, a simple PI controller seemed to be sufficient to achieve the desired objectives, this will be validated with the simulation results. The first step of this algorithm is a transformation so that the PI controller becomes a Static Output Feedback (SOF) controller. The SOF control problem, given some $\mathcal{H}_{\infty}$ performance criteria, is solved using the iLMI algorithm. The problem formulation of a PID controller into the SOF form is proposed in Zheng et al. (2002). For this system (1) the problem formulation in the SOF form is to find a controller of the form $u(t)=F y(t)$, where $F \in \mathbb{R}^{m \times p}$ is such that the closed loop of the system satisfies certain desired performances.

For a multivariable PI controller, $u$ is given by:

$$
u(t)=F_{1} y(t)+F_{2} \int_{0}^{t} y(\theta) d \theta
$$

To impose a $\mathcal{H}_{\infty}$ performance, the controller in (2) should satisfy a closed loop transfer function $\left(T_{z \omega}\right)$ constraint of the form: $\left\|T_{z \omega}(s)\right\|<\gamma$ for $\gamma>0$. The $\mathcal{H}_{\infty}$ control problem of system (1)-(2) is given by the following LMI:

$$
\left[\begin{array}{ccc}
P A_{c l}+A_{c l}^{T} P & P B_{c l} & C_{c l}^{T} \\
B_{c l}^{T} & -\gamma I & D_{c l}^{T} \\
C_{c l} & D_{c l} & -\gamma I
\end{array}\right] \prec 0
$$

with: $A_{c l}=A+B_{2} F C_{2}, B_{c l}=B_{1}+B_{2} F D_{21}, C_{c l}=C_{1}+$ $D_{12} F C_{2}$ and $D_{c l}=D_{11}+D_{12} F D_{21}$.

(3) is a BMI (Bilinear Matrix Inequality), the algorithm proposed in He and Wang (2006) is then used to transform this into an iterative LMI problem. A simplified version of this algorithm and the SOF control formulation proposed in Zheng et al. (2002) for a PI controller is used in this paper. For this we note:

$$
\bar{x}=\left[\begin{array}{c}
x(t) \\
\int_{0}^{t} y(\theta) d \theta
\end{array}\right] \text { and } \bar{y}=\left[\begin{array}{c}
C_{2} x(t) \\
\int_{0}^{t} y(\theta) d \theta
\end{array}\right]
$$


Then the system composed by $(1)$, setting $D_{21}=0$ without loss of generality, can be written as:

$$
\begin{gathered}
\dot{\bar{x}}=\bar{A} \bar{x}(t)+\bar{B}_{1} \omega(t)+\bar{B}_{2} u(t) \\
z(t)=\bar{C}_{1} \bar{x}(t)+\bar{D}_{11} \omega(t)+\bar{D}_{12} u(t) \\
\bar{y}(t)=\bar{C}_{2} \bar{x}(t)
\end{gathered}
$$

with:

$$
\begin{gathered}
\bar{A}=\left[\begin{array}{cc}
A & 0 \\
C_{2} & 0
\end{array}\right], \bar{B}_{1}=\left[\begin{array}{c}
B_{1} \\
0
\end{array}\right], \bar{B}_{2}=\left[\begin{array}{c}
B_{2} \\
0
\end{array}\right] \\
\bar{C}_{2}=\left[\begin{array}{cc}
C_{2} & 0 \\
0 & I
\end{array}\right], \bar{C}_{1}=\left[\begin{array}{ll}
C_{1} & 0
\end{array}\right] \\
\bar{D}_{11}=D_{11}, \bar{D}_{12}=D_{12}
\end{gathered}
$$

The algorithm proposed by He and Wang (2006) is divided in two parts. In the first part an initial decision matrix $P$ is found through an iterative process. The iteration procedure is used to solve the BMI problem using the following set of linearizing variables:

$$
L=P^{-1}, V_{1}=P \bar{B}_{2} F, V_{2}=F \bar{C}_{2} L
$$

Variables $P, L, V_{1}$ and $V_{2}$ are used to compute the initial decision matrix $P_{i}$ according to the following simplified algorithm proposed by He and Wang (2006):

Step 1) Define $i=1, P=P_{i}=I$ and $L=L_{i}=I$. Step 2) Find $P_{i}$ and $L_{i}$, subject to the LMI set (6) and minimizing trace $\left(P_{i} L_{i-1}+L_{i} P_{i-1}\right)$ :

$$
\begin{gathered}
{\left[\begin{array}{cc}
P_{i} & I \\
I & L_{i}
\end{array}\right] \geq 0} \\
{\left[\begin{array}{ccc}
\psi_{11} & P_{i} \bar{B}_{1} & \bar{C}_{1}^{T}+\bar{C}_{2}^{T} \bar{F}^{T} \bar{D}_{12}^{T} \\
* & -\gamma I & \bar{D}_{11}^{T} \\
* & * & -\gamma I
\end{array}\right]<0} \\
{\left[\begin{array}{ccc}
\xi_{11} & \bar{B}_{1} & L_{i} \bar{C}_{1}^{T}+V_{2}^{T} \bar{D}_{12}^{T} \\
* & -\gamma I & \bar{D}_{11}^{T} \\
* & * & -\gamma I
\end{array}\right]<0}
\end{gathered}
$$

with:

$$
\begin{aligned}
& \psi_{11}=P_{i} \bar{A}+\bar{A}^{T} P_{i}+V_{1} \bar{C}_{2}+\bar{C}_{2}^{T} V_{1}^{T} \\
& \xi_{11}=\bar{A} L_{i}+L_{i} \bar{A}^{T}+\bar{B}_{2} V_{2}+V_{2}^{T} \bar{B}_{2}^{T}
\end{aligned}
$$

Step 3) If trace $\left(P_{i} \times L_{i}\right)-n<\epsilon_{1}$, with $\epsilon_{1}$ a given tolerance, then an initial $P=P_{i}$ is found.

Step 4) An initial $P=P_{i}$ can not be found if between two iterations trace $\left(P_{i} L_{i}\right)-\operatorname{trace}\left(P_{i-1} L_{i-1}\right)<\epsilon_{2}$, with $\epsilon_{2}$ a given tolerance.

Step 5) Define $i=i+1$ and go to step 2 .

The second part of the algorithm computes the multivariable controller $F$.

Step 1) Define $k=1$ and $P=P_{k}=P_{i}$, the initial decision matrix.

Step 2) Find $F$ given $P_{k}$. This is, minimize $\alpha_{k}$ subject to the following LMI:

$$
\left[\begin{array}{ccc}
\phi_{11} & P_{k} \bar{B}_{1} & \bar{C}_{1}^{T} \\
* & -\gamma I & \bar{C}_{2}^{T} F^{T} \bar{D}_{12}^{T} \\
* & * & \bar{D}_{11}^{T}
\end{array}\right]<0
$$

with:

$$
\phi_{11}=P_{k} \bar{A}+\bar{A}^{T} P_{k}+P_{k} \bar{B}_{2} F \bar{C}_{2}+\bar{C}_{2}^{T} F^{T} \bar{B}_{2}^{T} P_{k}-\alpha P_{k}
$$

Step 3) If $\alpha_{k} \leq 0, F$ controller for $\gamma$ is found, STOP! Step 4) Define $k=k+1$. Find $P_{k}$ given $F$. This is, minimize $\alpha_{k}$ subject to the LMI (9).

Step 5) If $\alpha_{k} \leq 0, F$ controller for $\gamma$ is found, STOP! Step 6) Find $P_{k}$ given $F$ and $\alpha_{k}$. This is, minimize trace $\left(P_{k}\right)$ subject to the LMI (9).

Step 7) If $\left\|P_{k}-P_{k-1}\right\| /\left\|P_{k}\right\|<\delta$, then go to Step 8). Otherwise define $k=k+1$ and $P=P_{k-1}$, and go to Step 2). $\delta$ is a defined tolerance in the iteration process.

Step 8) The controller can not be found with this algorithm.

\section{2 $\mathcal{H}_{\infty}$ Controller}

$\mathcal{H}_{\infty}$ control is considered in this paper as a mean to compare several robust control techniques based on $\mathcal{H}_{\infty}$ performance with the optimal complete order controller. $\mathcal{H}_{\infty}$ control synthesis is well known in literature. In this paper the LMI formulation for the $\mathcal{H}_{\infty}$ control is used to find a controller that satisfies the constraints in (3). The LMI formulation of this problem is well described in Boyd et al. (1994) and Scherer et al. (1997).

\subsection{Reduced Order $\mathcal{H}_{\infty}$ Performance Controller}

A reduced order $\mathcal{H}_{\infty}$ controller is also considered for comparison. This type of controller is interesting because lower-order controller design is allowed, which is important for real implementation. The computation of this controller is difficult because the LMI constraints that describe the control problem formulation usually leads to a nonsmooth optimization problem. This controller is in contrast with the full order $\mathcal{H}_{\infty}$ control, where the controller order equals that of the plant. To compute this controller a MATLAB Toolbox called hifoo has been developed by Gumussoy et al. (2009) and is used in this paper to solve the $\mathcal{H}_{\infty}$ norm minimization problem.

\section{STUDIED SYSTEM}

\subsection{FC/SC Hybrid Power Generation System}

In this paper the studied system is a hybrid power generation system composed by a Fuel Cell and a Supercapacitor. System data and parameters, for a $1 \mathrm{~kW}$ hybrid FC/SC system at $24 \mathrm{~V}$ rated output voltage, were validated on a test-bench available in the LEPMI Laboratory. This testbench is presented in Sailler et al. (2008). Both sources are hybridized through parallel-connected DC-DC boost power converters. In this type of system the auxiliary source (Supercapacitor) should be able to supply a sufficient instant power to guarantee normal operation in the presence of important energy transients. A DC filter connects the output with the supplied DC load. As the choosen converter structure is fixed by our laboratory testbench system, it is considered that a third independent "perfectly controlled" flyback converter is used to recharge the supercapacitor. A reversible boost converter is not considered.

Both energy sources are modeled using their equivalent electrical circuit. For the FC the so-called double layer 


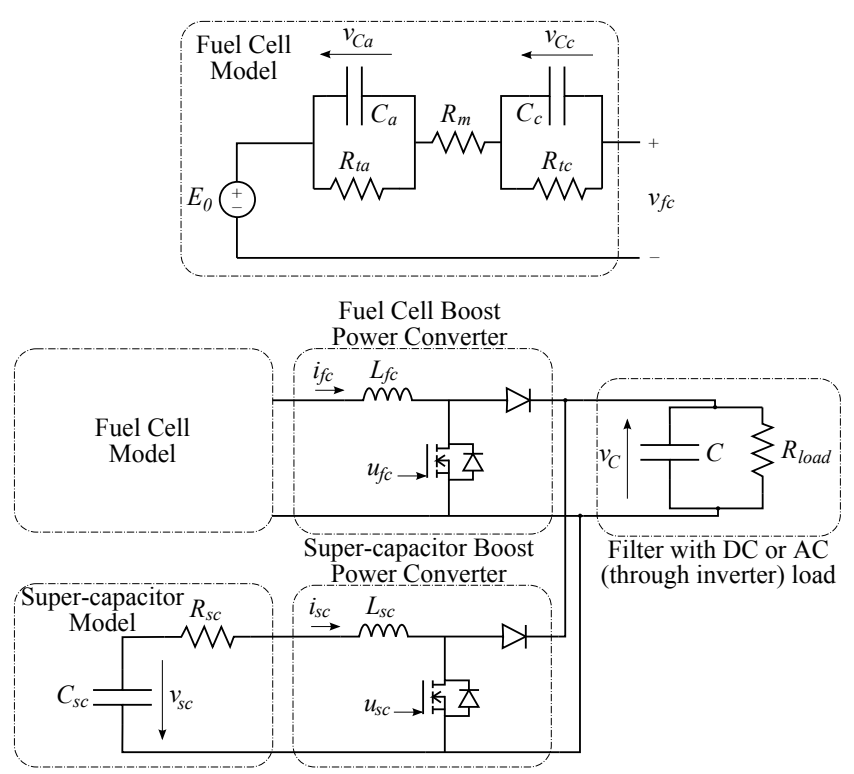

Fig. 2. Equivalent model of the complete studied system.

dynamical model is used, as in Sailler et al. (2008). The $\mathrm{SC}$ is modeled using a classical dynamical model. The equivalent model of the complete system is shown in Fig. 2

Average modeling (see Bacha et al. (1994)) is used to model the system in Fig. 2. State variables are: $V_{C_{c}}$ the double layer capacitor in the $\mathrm{FC}$ cathode, $V_{C_{a}}$ the double layer capacitor in the $\mathrm{FC}$ anode, $I_{f c}$ the $\mathrm{FC}$ output current, $I_{s c}$ the $\mathrm{SC}$ output current, $V_{s c}$ the $\mathrm{SC}$ voltage and $V_{C}$ the output filter capacitor voltage. The control inputs to the system are $\alpha_{f c}$ and $\alpha_{s c}$, the average values of the switching functions of the FC and SC power converters, $u_{f c}$ and $u_{s c}$ respectively. The load current $i_{\text {load }}$ is considered as the system output disturbance. The system average non-linear equations are given by:

$$
\begin{gathered}
\frac{d V_{C_{c}}}{d t}=\frac{1}{C_{c}}\left[I_{f c}-\frac{V_{C c}}{R_{t c}}\right], \frac{d V_{C_{a}}}{d t}=\frac{1}{C_{a}}\left[I_{f c}-\frac{V_{C a}}{R_{t a}}\right] \\
\frac{d I_{f c}}{d t}=\frac{1}{L_{f c}}\left[E_{0}-V_{C_{a}}-V_{C_{c}}-R_{m} I_{f c}-\left(1-\alpha_{f c}\right) V_{C}\right] \\
\frac{d I_{s c}}{d t}=\frac{1}{L_{s c}}\left[V_{s c}-R_{s c} I_{s c}-\left(1-\alpha_{s c}\right) V_{C}\right], \frac{d V_{s c}}{d t}=\frac{1}{C_{s c}} I_{s c} \\
\frac{d V_{C}}{d t}=\frac{1}{C}\left[\left(1-\alpha_{f c}\right) I_{f c}+\left(1-\alpha_{s c}\right) I_{s c}-i_{l o a d}\right]
\end{gathered}
$$

The system parameters are given in Table 1.

Table 1. FC/SC hybrid system parameters

\begin{tabular}{ccc} 
Parameter & Value & Units \\
\hline$E_{0}$ & 13.4 & Volts \\
$R_{m}$ & $1.28 \times 10^{-3}$ & $\Omega$ \\
$R_{t c}$ & $2.04 \times 10^{-3}$ & $\Omega$ \\
$R_{t a}$ & $4.72 \times 10^{-4}$ & $\Omega$ \\
$C_{a}=C_{c}$ & 2.12 & $\mathrm{~F}$ \\
$C_{s c}$ & 58 & $\mathrm{~F}$ \\
$R_{s c}$ & 0.019 & $\Omega$ \\
$L_{f c}=L_{s c}$ & 50 & $\mu \mathrm{H}$ \\
$C$ & 37.6 & $\mathrm{mF}$ \\
\hline
\end{tabular}

\subsection{System Scaling}

Due to the important magnitude differences between several electric system components (capacitors, inductance and resistances for example), system scaling could be an important step before the control problem formulation. This will improve the conditioning of the problem and, thus, improve the optimizations algorithms performance. System scaling was performed in this paper using the prescale function in the MATLAB Control System Toolbox (Version 8.4 - Release 2009b). Inverse scaling of the controller to the original scale is not needed since output feedback control is considered.

\subsection{Current control strategy}

Simple PI control of DC boost power converter is not easy, in particular due to the boost converter zero dynamics. The current control strategy implemented in the available platform consists in a PI control design, where the dynamics of both converters are assumed to be decoupled (a PI controller is computed for each subsystem). However, when integrated, closed loop stability problems could arise on the parallel converter configuration using the voltagemode control. And the retuning of both PI controllers to ensure the stabilizing of the MIMO system is not an easy task. A common approach is to use a multi-loop feedback strategy with an additional stabilizing current control loop. For a stability analysis of PI control of DCDC converters see Alvarez-Ramirez et al. (2001). Control implementation for several structures with energy management are proposed in the literature, see Valero et al. (2006), Pera et al. (2007) or Thounthong and Rael (2009).

The multi-loop feedback control strategy used in this paper for control implementation, for both, the FC and the SC DC boost converters, are presented in Fig. 3 and 4 respectively.

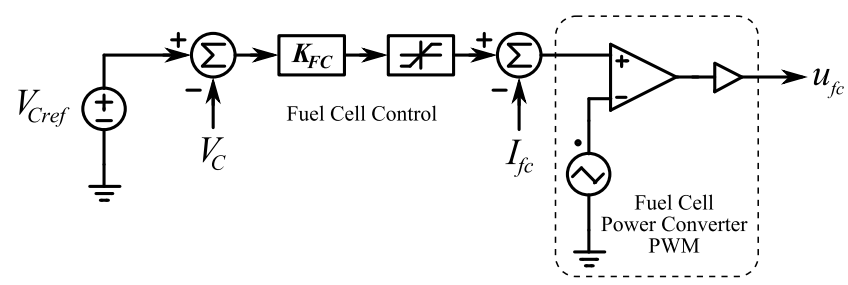

Fig. 3. Control strategy for the FC DC boost converter.

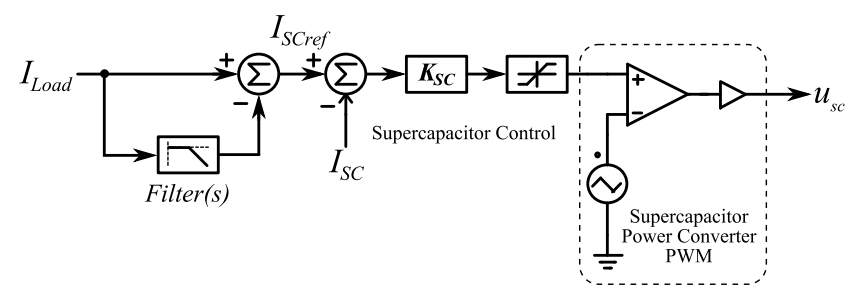

Fig. 4. Control strategy for the SC DC boost converter.

The low-pass control filter in Fig. 4, allows computing the (high frequency) SC reference current $I_{S C r e f}$, that equals the fast transient dynamics in the load. The filter chosen for the studied system has a cutoff frequency of $1 \mathrm{~Hz}$ and is given by: 


$$
\text { Filter }(s)=\frac{0.001 s+6.283}{s+6.315}
$$

The PI controllers designed for this configuration are given by:

$$
\begin{aligned}
& K_{F C}(s)=\frac{27.46 s+100}{s} \\
& K_{S C}(s)=\frac{100 s+1000}{s}
\end{aligned}
$$

These PI controllers have been computed using classical "hand made" SISO tuning methods (gain margin $G M>6 d B$, phase margin $P M>45^{\circ}$ ), assuming that the $\mathrm{FC} /$ Boost \#1 converter system and the SC/Boost \#2 converter system have some decoupled dynamical behaviors. However, stability and robustness performances can not be guaranteed for the MIMO system.

\section{PROPOSED CONTROL DESIGN METHODOLOGY}

\subsection{Problem Formulation}

The MIMO robust control synthesis is based on the general control configuration adapted to the hybrid $\mathrm{FC} / \mathrm{SC}$ system. The controlled outputs are the voltage $V_{C}$ and the SC current $I_{s c}$. The control objective is to keep a desired output voltage level and to control the SC current in order to provide the fast transient currents in the case of a load disturbance. Load transient rejection is important for the FC in order to avoid harmful operating conditions, Wang and Nehrir (2007). All controllers, including the classic PI control presented before, are designed to avoid exceeding normal operational output voltage ranges $( \pm 5 \%$ of rated output voltage is considered in this paper). In particular, the PI iLMI controller is designed to guarantee output voltage ranges and a stabilization time of $0.5 \mathrm{sec}$. The chosen configuration is shown in Fig. 5. The different weighting functions for this system, selected to guarantee the desired time/frequency performance described before, have been chosen as:

$$
\begin{aligned}
W_{\text {perf }} & =\frac{0.8 s+0.1}{s+0.001} \times I_{2} \\
W_{u_{1}} & =\frac{s+15.79}{0.01 s+15.71} \\
W_{u_{2}} & =\frac{s^{2}+3.947 \times 10^{5} s+6.2 \times 10^{6}}{0.01 s^{2}+3.927 \times 10^{5} s+6.169 \times 10^{4}}
\end{aligned}
$$

The iLMI algorithm yields a solution for the multivariable PI controller after five iterations, with a value of $\gamma=1.45$. $\mathcal{H}_{\infty}$ controller for full and reduced order are also computed using the weighting functions presented before. The $\mathcal{H}_{\infty}$ full order controller found has 11 states and an optimal $\gamma=$ 1.25. The reduced order $\mathcal{H}_{\infty}$ controllers were computed after two iterations using the hifoo function with the $\mathcal{H}_{\infty}$ norm minimizing option. The Bode diagrams of the different controllers are presented in Fig. 6. The frequency performance of the controllers indicate the importance of the MIMO controllers, when compared to the diagonal classic PI control.

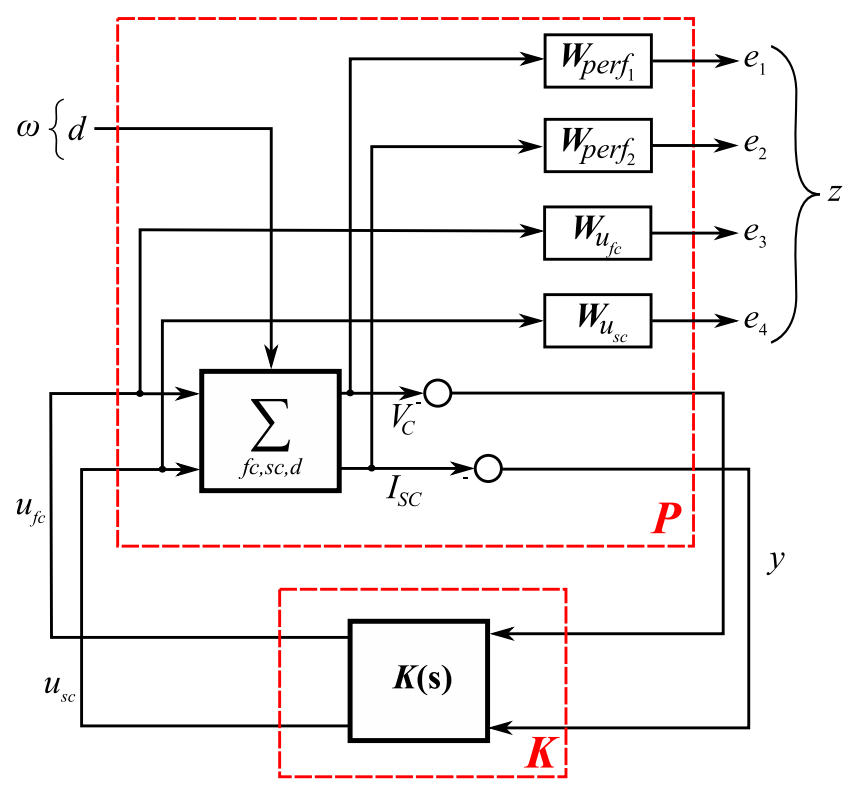

Fig. 5. Multivariable hybrid FC/SC system general control configuration.

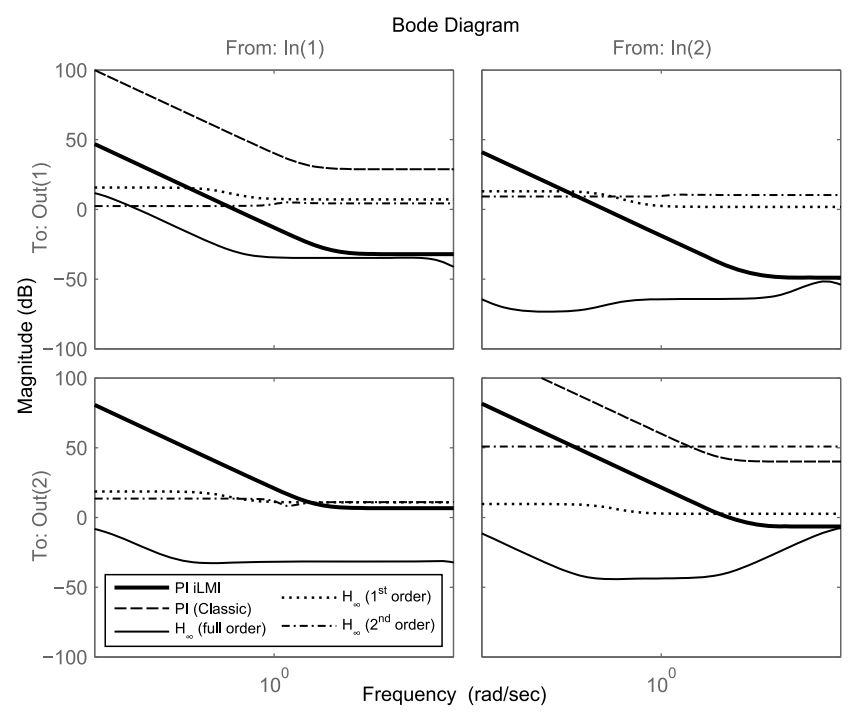

Fig. 6. Singular values plots of the different controllers.

For the studied system shown in Figure 5, the sensitivity functions are defined by:

$$
S_{1}=\frac{V_{C}}{d}, S_{2}=\frac{I_{S C}}{d}, S_{1} K_{1}=\frac{u_{f c}}{d}, S_{2} K_{2}=\frac{u_{s c}}{d}
$$

The Bode diagrams of the MIMO sensitivity functions $S$ and $S K(s)$, are shown in Fig. 7 and Fig. 8 respectively. Results show how the shaping of $\mathcal{H}_{\infty}$ performance is straightforward for the PI iLMI and the full order $\mathcal{H}_{\infty}$ controllers using the templates weighting functions. These figures also show how performances are not entirely met using the reduced order $\mathcal{H}_{\infty}$ controllers, and the classical PI control. In contrast, the PI iLMI controller, maintains a gain close to the one of the optimal full order $\mathcal{H}_{\infty}$ controller, with a small resonant peak. 


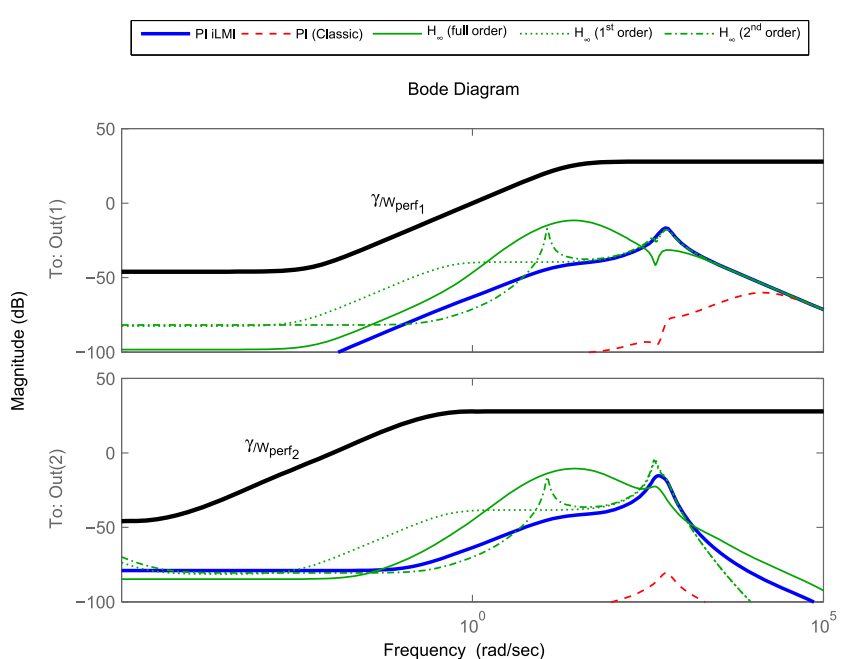

Fig. 7. Singular values plots for sensitivity functions $S_{1}$ and $S_{2}$.

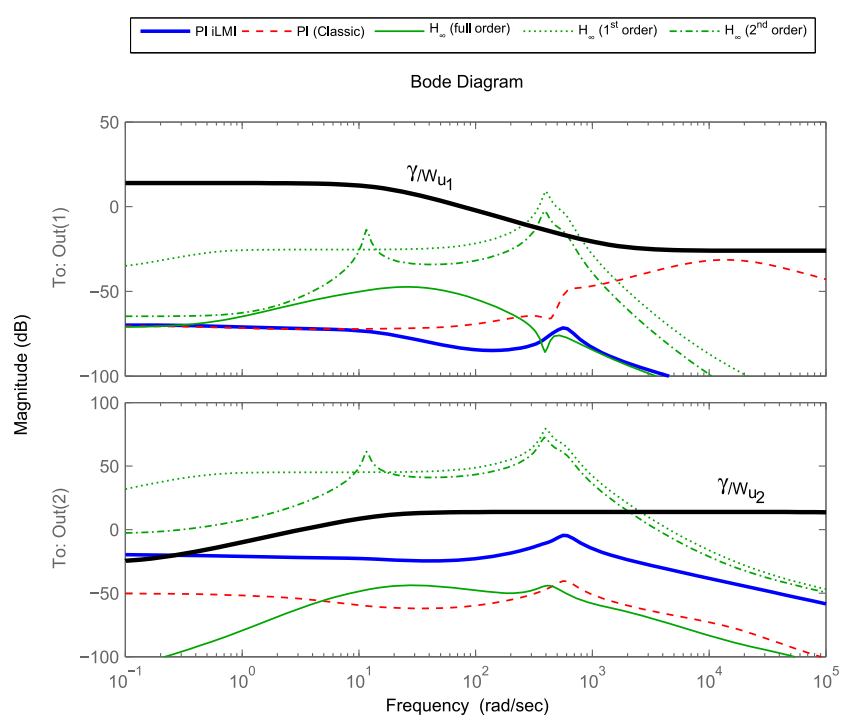

Fig. 8. Singular values plots for sensitivity functions $S_{1} K_{1}(s)$ and $S_{2} K_{2}(s)$.

\subsection{Simulation Results}

Simulation results for a $10 \%$ load step using the linearized closed loop system model, are shown in Fig. 9. The different controllers are compared. Note that with the full order $\mathcal{H}_{\infty}$ controller the settling time can be improved by relaxing the optimization constraint parameter $\gamma$. Time response of the classic PI control is similar to that of the $1^{\text {st }}$ order $\mathcal{H}_{\infty}$ control and is not shown for the sake of simplicity.

Simulation tests and validations were also performed using the non-linear average and the complete topological (real) model of the studied system. It is worth noting that a second stabilizing current loop (multi-loop feedback) is needed when classic PI control is to be implemented. This is not required to obtain stable performance in the voltagemode control with the robust control strategies proposed in this paper. In the case of the PI iLMI control, the stability condition is included in the LMI formulation, so that stability is always guaranteed.

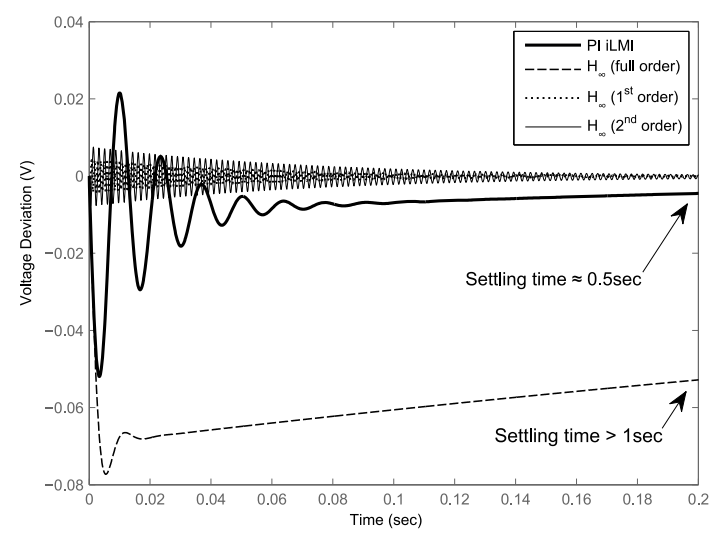

Fig. 9. Output voltage response to a load step disturbance.

The PI and the full order $\mathcal{H}_{\infty}$ controllers are compared for validation using the non-linear average model of the studied system. Simulation results are shown in Fig. 10 for load steps of $10 \%$ at $t=2 \mathrm{sec}$ and $100 \%$ at $t=$ 6 sec. The average non-linear model was validated using the complete topological model and the control strategies shown in Figs. 3 and 4. However, the stabilizing control loop was not necessary for the PI iLMI implementation. Results show the effectiveness of the proposed control, and control objectives are successfully achieved. The SC current contributes effectively to the load transient and output voltage is maintained within acceptable ranges.
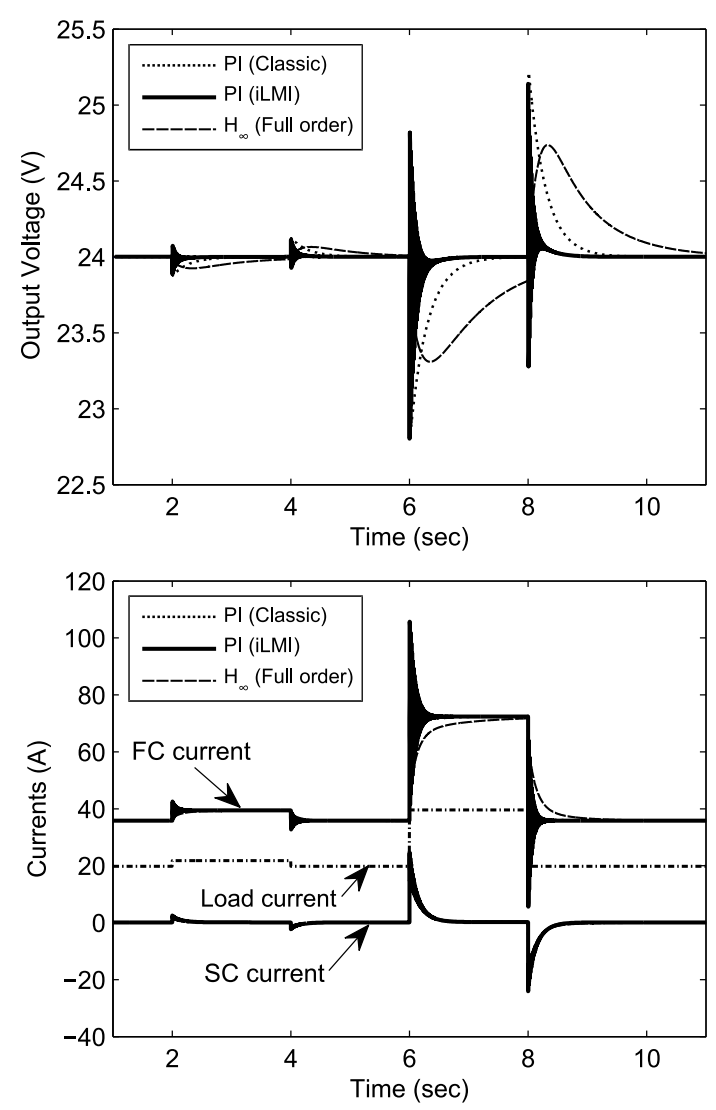

Fig. 10. Time simulation results using the complete nonlinear average model. 


\section{ROBUSTNESS ANALYSIS}

The robustness analysis in the presence of model uncertainties is carried out using $\mu$-analysis. These techniques are detailed in Skogestad and Postlethwaite (1996) and Zhou (1998), and are applied to practical problems in Gadoura et al. (2002) and Sename and Dugard (2003) for example. Uncertainties are modeled with the unstructured input-multiplicative form and are represented by the uncertainties weights. This configuration is presented in Fig. 11.

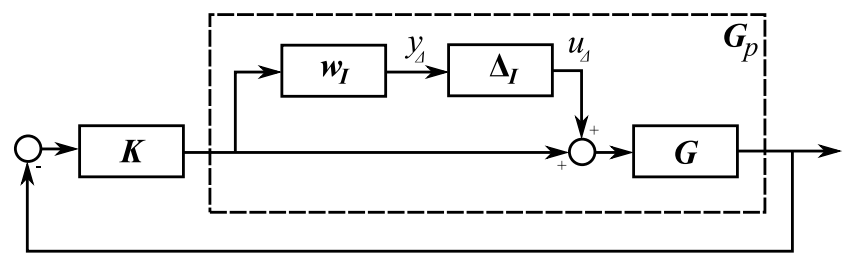

Fig. 11. Modeling uncertainties.

The general control configurations for the perturbed system and for the robust performance analysis is presented in Fig. 12. For the FC/SC hybrid system, the proposed configuration for $\mu$-analysis is shown in Fig. 13. The weighting functions for uncertainties modeling are computed using the ucover function in the MATLAB Control System Toolbox. The weighting functions obtained and the sampled uncertain transfer functions of the system are presented in Fig. 14.
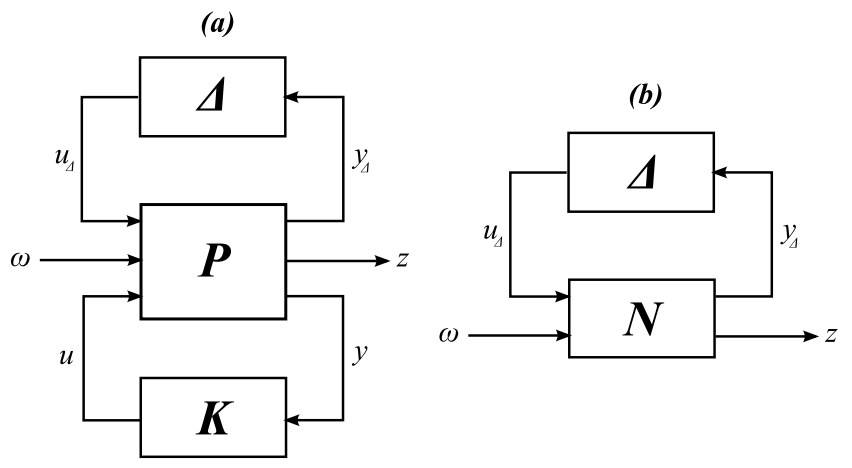

Fig. 12. General control configurations of the perturbed system (a) and the robust performance (b).

Robust stability and robust performance plots for parametric uncertainties of $10 \%$ in $C, C_{s c}, L_{f c}$ and $L_{s c}$, and of $20 \%$ in $R_{t a}, R_{t c}, R_{m}$ and $R_{s c}$, are presented in Figs. 15 and 16 .

From these results, the initial assumption of a better robustness performance using the PI iLMI and the full order $\mathcal{H}_{\infty}$ is verified. The robust stability plots shows a maximum value of $\mu=0.8$ for the PI iLMI control. This means that the closed loop system remains stable with larger uncertainties up to $125 \%$ of the modelled uncertainties. For this uncertainty case we cannot conclude on the robust performance (RP), since $\mu=1.8>1$ for the PI iLMI control. However it is the more robust one after the full order $\mathcal{H}_{\infty}$ controller, which guarantees RP. For the other controllers we can check that RP is satisfied with a lower uncertainty set, for example for $5 \%$ uncertainty in $C, C_{s c}, L_{f c}$ and $L_{s c}$, and of $10 \%$ in $R_{t a}, R_{t c}, R_{m}$ and $R_{s c}$.

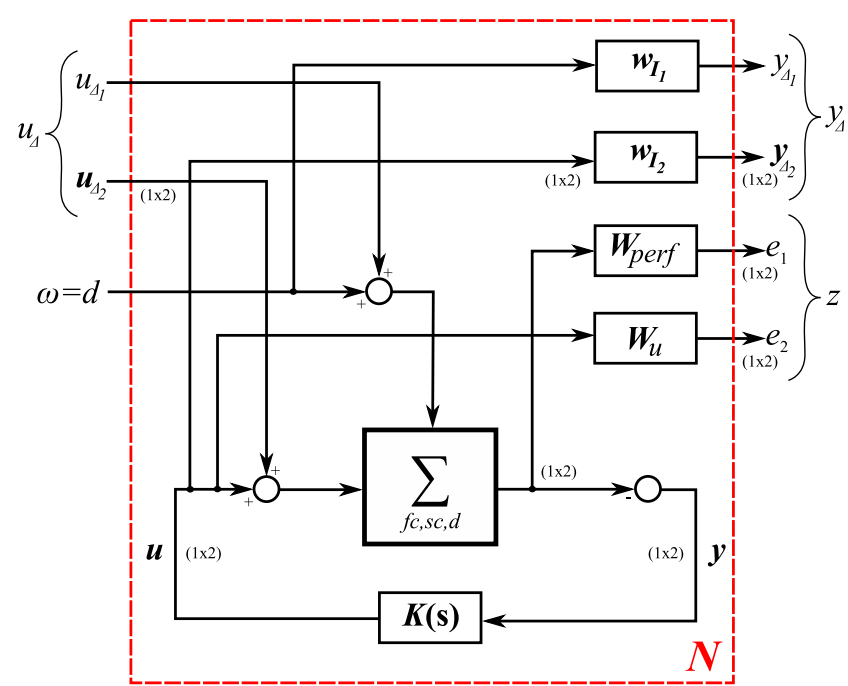

Fig. 13. Modeling uncertainties for the FC/SC hybrid system.
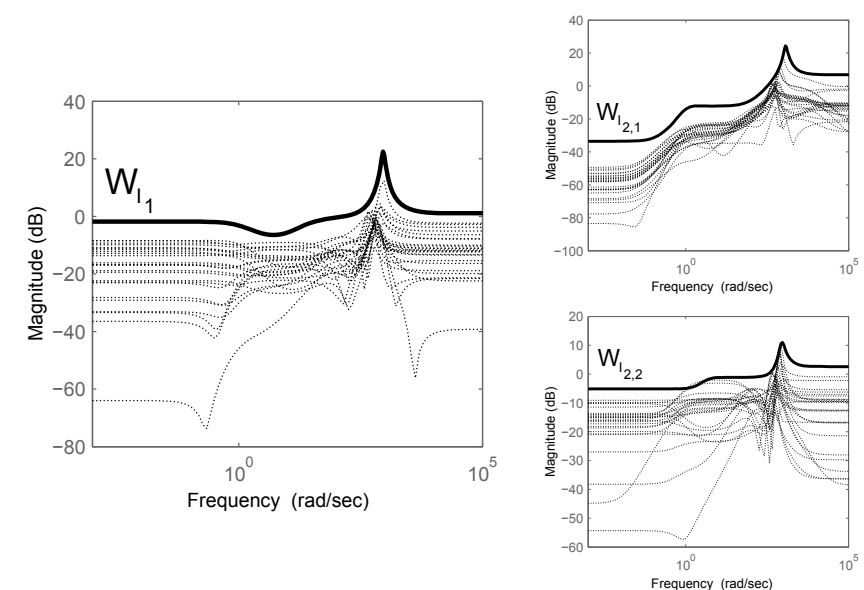

Fig. 14. Weighting functions for uncertainties modeling.

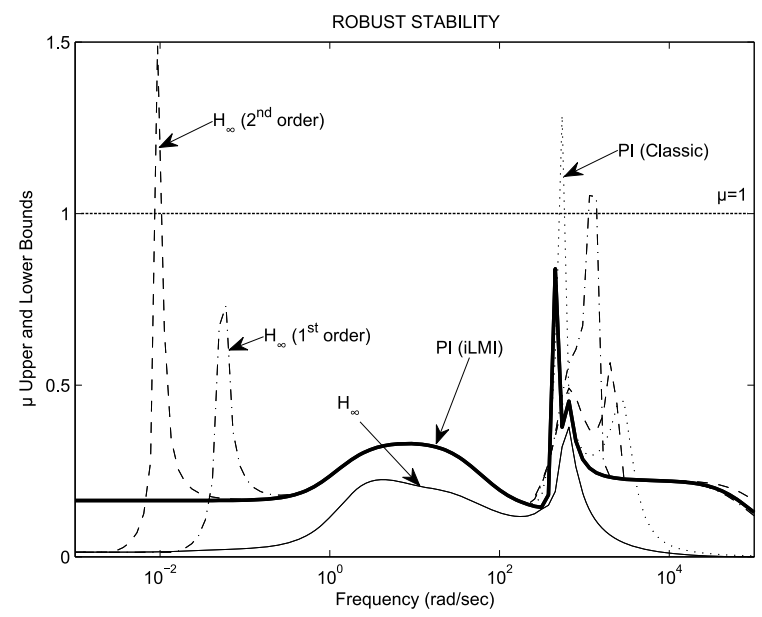

Fig. 15. Robust stability plot.

Robustness tests were also performed for uncertainties in the system load. Similar results were obtained in terms of controllers robustness. Robust stability is guaranteed for $110 \%$ uncertainty in the load modeled as a constant resistance $i_{\text {load }}=V_{C} / R$ using the PI iLMI control, this is not true for classic PI control. 


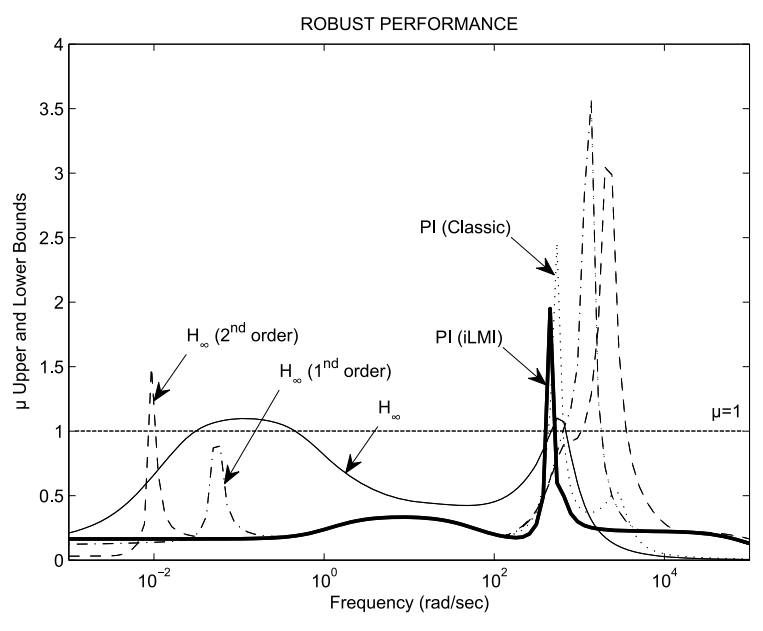

Fig. 16. Robust performance plot.

\section{CONCLUSION}

A complete time/frequency analysis, including a robustness analysis, has been performed on several control methods. An important control approach has been proposed using simple MIMO PI control with $\mathcal{H}_{\infty}$ performance. Simulation results show the effectiveness of the proposed control strategy over classic PI tuning methods. This multivariable robust PI control could be developed as a generalized control design technique, improving timeconsuming design procedures. The practical advantages of robust control, on complex real problems, can be more easily addressed using the proposed methodology. The use of the generalized MIMO PI control methodology proposed in this paper can be extended to other several control strategies for power converters, as a hybrid power generation system connection to the utility network through an inverter. Future experimental tests are envisaged for control validation, using the available Fuel Cell test-bench.

\section{REFERENCES}

Alvarez-Ramirez, J., Cervantes, I., Espinosa-Perez, G., Maya, P., and Morales, A. (2001). A stable design of PI control for DC-DC converters with an rhs zero. Circuits and Systems I: Fundamental Theory and Applications, IEEE Transactions on, 48(1), 103-106.

Bacha, S., Brunello, M., and Hassan, A. (1994). A general large signal model for DC-DC symmetric switching converters. Electric Machines and Power Systems, 22, $493-510$.

Boyd, S., Ghaoui, L.E., Feron, E., and Balakrishnan, V. (1994). Linear Matrix Inequalities in System and Control Theory. Society for Industrial and Applied Mathematics, Philadelphia.

Gadoura, I., Suntio, T., and Zenger, K. (2002). Robust control design for paralleled DC/DC converters with current sharing. In Proceedings of the 15th IFAC World Congress on Automatic Control.

Gumussoy, S., Henrion, D., Millstone, M., and Overton, M. (2009). Multiobjective robust control with HIFOO 2.0. In Proc. of the IFAC Symposium on Robust Control Design.

He, Y. and Wang, Q.G. (2006). An improved ILMI method for static output feedback control with application to multivariable PID control. IEEE Trans. on Automatic Control, 51(10), 1678-1683.
Hissel, D., Turpin, C., Astier, S., Boulon, L., and et al. (2008). A review on existing modeling methodologies for PEM fuel cell systems. In Fundamentals and Developments of Fuel Cells Conference 2008 - FDFC2008.

Middlebrook, R.D. (1987). Topics in multiple-loop regulators and current-mode programming. Power Electronics, IEEE Transactions on, PE-2(2), 109-124.

Pera, M., Candusso, D., Hissel, D., and Kauffmann, J. (2007). Power generation by fuel cells. Industrial Electronics Magazine, IEEE, 1(3), 28-37.

Petrovic, B. and Rakic, Z. (2005). Linear robust control of DC/DC converters: Part I deterministic switching. Electrical Engineering (Archiv fur Elektrotechnik), $87(2), 57-68$.

Rafiei, S., Ghazi, R., Asgharian, R., Barakati, M., and Toliyat, H. (2003). Robust control of DC/DC PWM converters: a comparison of $\mathcal{H}_{\infty}, \mu$, and fuzzy logic based approaches. In Control Applications, 2003. CCA 2003. Proceedings of 2003 IEEE Conference on, volume 1, 603-608.

Sailler, S., Druart, F., Riu, D., and Ozil, P. (2008). Simulation of a PEMFC-super capacitor hybrid system. In 18th European Symposium on Computer Aided Process Engineering ESCAPE 18.

Scherer, C., Gahinet, P., and Chilali, M. (1997). Multiobjective output-feedback control via lmi optimization. Automatic Control, IEEE Trans. on, 42(7), 896-911.

Sename, O. and Dugard, L. (2003). Robust $\mathcal{H}_{\infty}$ control of quarter-car semi-active suspensions. In Proc. of the European Control Conference, Cambridge, UK.

Skogestad, S. and Postlethwaite, I. (1996). Multivariable Feedback Control: Analysis and Design. Jhon Wiley \& Sons, New York, USA.

Song, Y., Han, S., Li, X., Park, S., Jeong, H., and Jung, B. (2007). A power control scheme to improve the performance of a fuel cell hybrid power source for residential application. In Power Electronics Specialists Conference, 200\%. PESC 200\%. IEEE, 1261-1266.

Suh, K.W. and Stefanopoulou, A.G. (2005). Coordination of converter and fuel cell controllers. International Journal of Energy Research, 29(12), 1167-1189.

Takegami, E., Tomioka, S., Watanabe, K., Higuchi, K., Nakano, K., and Kajikawa, T. (2004). Robust control of DC-DC converter by good approximate 2-degree-offreedom system. In SICE 2004 Annual Conference, volume 1, 614-619.

Thounthong, P. and Rael, S. (2009). The benefits of hybridization. Industrial Electronics Magazine, IEEE, $3(3), 25-37$.

Valero, I., Bacha, S., and Rulliere, E. (2006). Comparison of energy management controls for fuel cell applications. Journal of Power Sources, 156(1), 50-56. Selected papers from the 2nd France-Deutschland Fuel Cell Conference.

Wang, C. and Nehrir, M.H. (2007). Load transient mitigation for stand-alone fuel cell generation systems. IEEE Trans. on Energy Conversion, 22, 864-872.

Zheng, F., Wang, Q.G., and Lee, T.H. (2002). On the design of multivariable PID controllers via LMI approach. Automatica, 38, 517-526.

Zhou, K. (1998). Essentials of Robust Control. Prentice Hall, New Jersey. 